\title{
Wellness Tourism in Puncak West Java Indonesia Area
}

\section{Sri Pujiastuti}

Bogor Institute of Tourism, Bogor Indonesia

Corresponding author: sripujiast29@gmail.com

\section{ARTICLE INFO}

Received

30 July 2019

Accepted

07 September 2019

Available online 30 September 2019
Wellness tourism is one of the attractions that has become a trend both in Indonesia and in the world, in addition to providing business opportunities and can also have a positive impact on health and fitness that have not been managed optimally. The area that has the potential of wellness tourism is in Puncak area which is found in West Java, especially in the PTP Nusantara VIII Gunung Mas area, which has a tea plantation as well as a spring in it. The distance that is not too far from the capital city of Jakarta, makes this area a tourist destination for escape or relaxation from routine activity. This study uses a descriptive qualitative approach where data collection uses in-depth interviews, documentation and review literature from various sources and where the results obtained are presented thoroughly to get a complete picture of the potential of wellness tourism in the peak regions. The results obtained in this study are that the management and regulation of wellness tourism are felt appropriate to be developed in this area, due to the natural potential possessed in accordance with the background or motivation of tourists who come to this area. In addition, wellness tourism that is based on nature and managed jointly with the local community will contribute positively to the improvement of the economy of the surrounding community and environmental preservation that will be maintained over time.

Keywords: Wellness Tourism, Puncak area

\section{INTRODUCTION}

\section{Background}

The progress of a technology makes people's lifestyles unhealthy because everything is facilitated by technology, start from getting up from sleep and getting back to sleep almost all our routine activity become unhealthy lifestyles, many people do activities for wellness to get out of the fatigue of routine daily activities.

Wellness tourism has now become a lifestyle and according to the Global 
Wellness Economy, predicts that by 2015, a wellness lifestyle will reach a market of around \$ 118.8 trillion which will concentrate on North America, Asia and Europe, more details can be seen below.

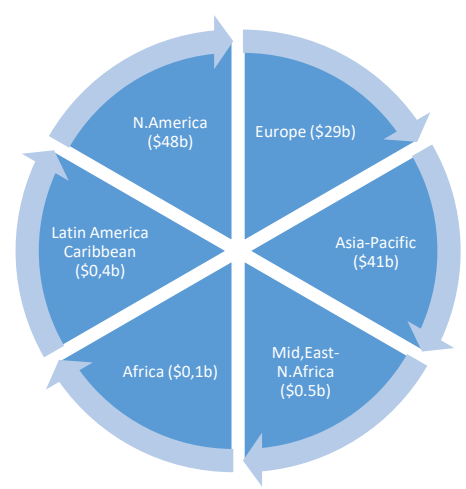

Figure 1. Life style wellness

Source: Global Wellness Institute, 2015

Based on the diagram above, it can be seen that more and more people are aware of the importance of wellness tourism, it is clear as illustrated by the diagram above Asia Pacific revenue in the field of wellness tourism reaches a figure of over \$41 billion and Indonesia has reached \$ 922.9 in 2016 and also this is not just a good for health but it also turns out to be a promising business because it generates substantial income both for stake holder and for the country. Regarding the tourism and leisure industry, the seniortargeted market provides superior and innovative business opportunities for service and products within the traditional tourism and leisure industry ( (Szmigin; Carrigan , 2001; Feng, Hsiang Chang;
Hsiou, Hsiang Liu; Kaung, Hwa Chen, 2013).

Indonesia especially West Java which is Gunung Mas accordance with the requirements on location and environment can be create as wellness tourism and with state holder corporation for sustainable development, so that the target and the results will be maximal, then this will be a promising income as a good business, because until now its consumers already exist and revenue in the wellness field has been proven based on data the author got in 2016.

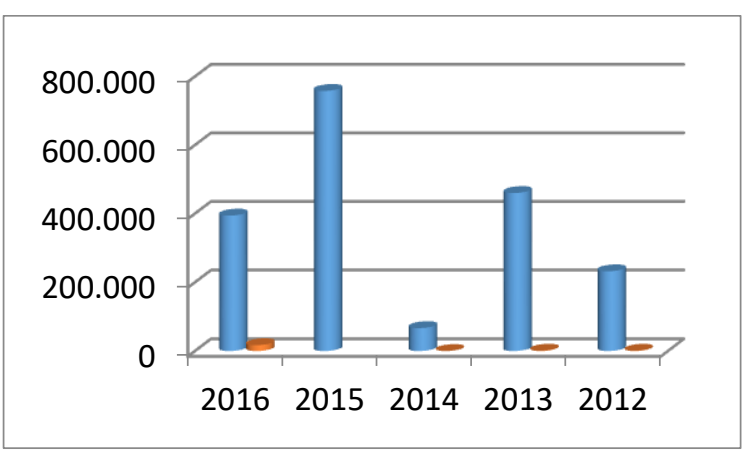

Figure 2. Data on the number of visitors to Gunung Mas

Source of Regency Tourism Office Bogor, 2017

Refers to diagram above, it can be seen that the number of visitors experienced an increase and decrease in 2012 and 2014 and experienced another increase in 2015 and a slight decrease in 2016. But with this data proves that there are still many visitors who come to enjoy the Gunung Mas , Gunung Mas is one of e-ISSN: 2407-392X. p-ISSN: 2541-0857 
the leading tourist attractions, especially in the tea plantation sector which is a natural tourism that has the potential to be developed. And it has become the current trend to be able to live healthy and fit.

Bogor Puncak area is one of the areas that become the magnet of the capital city residents and the surrounding community to visit, although to reach this location will be faced with extraordinary congestion, but does not ignite the spirit of visitors not to stop and enjoy the fresh air in the Gunung Mas, the more visitors who come to the location will automatically have a positive impact on the surrounding population, because it can provide better income.

Location of gunung mas, can be reached within 45 minutes until 1(one) hour from Jakarta. Gunung Mas Puncak Tea Plantation is one of the largest tea plantations in West Java, established in 1910 and is one of the business units of PT. Perkebunan Nusantara VIII, whose management is under a State-Owned Enterprise (BUMN). Gunung Mas Agro Tourism is one of the tourist attractions in the Puncak area. Tourist attractions can be divided into 3 (three) parts, namely: 1). Nature is a tourist attraction of the creation of God Almighty which is in the form of a natural state of flora and fauna. 2). Culture is an attraction of special interest tours such as hunting, mountain climbing, caves, industry and crafts, shopping places, fast water rivers, places of worship, places of pilgrimage and others. 3). Man Made is a tourist attraction created by human beings in the form of museums, historical relics, art and culture, agro tourism, hunting tours, nature adventure tours, recreational parks and entertainment complexes

Gunung Mas Puncak combines between Culture and Man Made, Culture because there is a Ciburial spring that comes from nature, Man Maid because the Gunung Mas is the result of human work in the form of agro tourism. According to data from the Bogor Regency Tourism Office, the number of visitors coming to Puncak, especially Gunung Mas, is not stable, it up and down.

Based on data above the tourist attraction of Gunung Mas until now still in demand to be visited by tourists both domestic tourists and foreign tourists. Judging from the location, Gunung Mas Puncak is very appropriate when used as a fitness tour.

Based on the explanation above, it can be concluded as follows: (i). Is Gunung Mas Puncak has the potential to be used as a wellness touriam, (ii). Can it have an economic impact on the 
surrounding population (iii). What the Government can provide to support Gunung Mas Puncak is a potential for wellness tourism

\section{Research Objectives}

This study aims to find out whether Gunung Mas Puncak has the potential to be developed into a wellness tourism and whether it has an economic impact on the surrounding population and the role and support of the government to make Gunung Mas Puncak a potential for wellness tourism.

\section{LITERATURE REVIEW}

\section{Wellness Tourism}

Wellness can be defined as the balanced state of body, spirit and mind, including such holistic aspects and dimensions as self-responsibility, physical fitness/beauty care, healthy nutrition, relaxation, mental activity and environmental sensitivity as fundamental constitutional elements ( Kulezyeki, Luck, Rodrigues, \& Kastenholz, 2010) refer to the theory above it clearly mention in wellness there is 7 (seven) element who support each other for wellness tourism. Without those element, we couldn't say it potential for wellness tourism development. Physical fitness/beauty care in several study it refers to one hiking exercise, Hiking tones muscles, contributes to loss of weight, reduction of stress, improvement of both sleep and mental alertness ( (Hansmann et al., Herzog et al, Aurea, Elisabeth, \& and Apolonia, 2010). Gunung Mas is the appropriate place for hiking because they have Mountain tea for tea walk guide by tour guide, actually the environment and the view is one of tourist attraction, but they have problem with infrastructure who supported in wellness tourism and to fix it and develop still on discussion because it quite expensive that's way, need corroboration with stake holder, infrastructure is one the most important for tourism destination to attract, visitor to come, good infrastructure especially in walking trails will create memorable experience indirect, Additionally, walking trails are infra-structures that are less expensive to develop than alternative wellness facilities, e.g. SPAs, and more appropriate to be integrated in the rural tourism context, also given the possibility of combining within the hiking experience culture and nature experience ( (Rodrigues et al., 2010)

Wellness tourism has become a trend lately, most people from big city looking something different for refreshment and also good environment with fresh air on it and most of them want to have 
refreshment outside from their busy daily activity

Wellness tourism is all about the happiness and from the happiness we can create quality of live. Wellness includes various related concepts, such as wellbeing, happiness, quality of live, holistic practice, and perceptual (Adam, ; Kaung, Hsiou, \& Feng, 2013). The most important in wellness is to made quality of live start from Mind, Body, Health, Relaxation ending with happiness. Same opinion mention from (Messerli \& Oyama, 2004) "viewed wellness as a way of live to create a healthy body, soul and mind through acquired knowledge and positive intervention. Same opinion with (Smith and, Boulay, \& Dr.M.Hritz, 2012), definition of wellness tourism, this study specifically defined wellness tourism as travel for the purpose of health on one or more of the six wellness dimensions; physical, social, intellectual, emotional, psychological, and spiritual. Recently, other studies have focused on escapism, how travel may benefit an individual's psychological wellness by relaxing at the beach, a spa or mountain areas ( (Pechlaner \& \& Bachvarov \&, 2006); (Boulay \& Hritz, 2012). Because most of visitor travel focused on escapism to relax axing by visit tourism destination such as mountain to full fill what they need.
Motivation factor are internally driven travelers travel because the destination it self has attribute that meet their need. Push and pull factors have traditional been used to examine relationships between motivation and destination choices ( (Crompton, 1979); (Boulay \& Hritz, 2012). Destination will be chosen by visitor because there is motivation from tourism attraction.

\section{METHODOLOGY}

\section{Research Location and Time}

This research is located at Agrowisata Gunung Mas Puncak. This study use a descriptive qualitative data include: information, location, opinions, ideas, expression, impression and criticism that come from citizen and community surrounding Puncak area especially Agrowisa Gunung Mas.

\section{Data Collecting}

Primary data are derived from the community and visitor Gunung Mas while secondary data are geatherd through the study of literature and other previous studies. In this research using data collection techniques as follows:

1. Observation, direct observation to the location looking information related with wellness tourism based on dimension

e-ISSN: 2407-392X. p-ISSN: 2541-0857 
2. In-depth interviews based on guidelines interview with visitors, management and community of Agrowisata Gunung Mas. Through this interview we will get deeper information and in detail

3. Document, based on document in photos and video

4. Literature, from theory and the result of previous research and writing which can be use for this research based on any kind of reference related

\section{Data Analysis}

The technique used to analyze the data is a descriptive qualitative analysis, that is all the collected data is analyzed and searched the threads with the theories provided so as to presented and draw conclusions based on the observation so it could become wellness tourism

\section{RESULTS}

Interviews were conducted to 30 informants at different times with the following explanation, Gunung Mas Puncak area has the potential to be developed, this is stated by several interviews that the interview writer, and is visited by many visitors because of seeing in terms of natural conditions and fresh air, which cannot be possessed by other tourist attractions, refers to "Additionally , walking trails are infra-structures that are less expensive to develop than alternative wellness facilities, e.g. SPAs, and more appropriate to be integrated in the rural tourism context, also given the possibility of combining within the hiking experience culture and nature experience ") (Rodrigues et al., 2010)because only Gunung Mas Agro Tourism has a good natural culture so that its natural potential is far more prominent than the tourism others, who are around this is the same like theory "Wellness can be defined as the balanced state of body, spirit and mind, including such holistic aspects and dimensions as self-responsibility, physical fitness/beauty care, healthy nutrition, relaxation, mental activity and environmental sensitivity as fundamental constitutional elements" ( (Kulezyeki, Luck, Rodrigues, \& Kastenholz, 2010)

To attract tourists who visit, then in addition to the mountains of tea, look for other potential that can attract tourists, but still express what is already in nature today and one of the tourist attractions that can be developed for the time being, which many contain properties for body freshness. Water that comes out of the soil as a spring, contains many properties, especially for the freshness of the body, 
because it is a factor that many visitors come to enjoy the fresh spring, springs that come out of the ground have good health benefits and also the water can be drunk directly without having to be cooked first, Development must be supported by the Department of Tourism, on condition that it does not damage nature and the development must have a positive impact on the surrounding community, especially affecting the economy and regional income.

Based on the results of interviews from several information, it can be said that the the Gunung Mas Agro Tourism area can directly affect the body's freshness.

The facilities that exist in the tourist attraction, are still very simple, need a lot of renovation so that the visitors who come can feel the comfort in traveling, lack of facilities. the success of a tourist area depends very much on the facilities owned by tourist destinations, the facilities that have been owned to date are still very minimal, therefore, visitors those who arrived were still few, up and down the percentage, and for the time being the visitors who arrived, many came during the weekends on Saturday and Sunday, New facilities or additions from existing ones are very important, so it can develop according to current tourism development. Based on the above interview it is clear that, facilities are very important in a tourist attraction, besides being able to attract tourists to come to visit, it can also provide an unforgettable experience by visitors, and is expected to attract tourists, then the income of the people around them can increase.

Facilities are very important in a tourist attraction besides being able to attract tourists to come to visit, it can also provide an unforgettable experience by visitors, and is expected to attract tourists, then the income of the people around them can increase. access to the location, is one of the considerations of visitors to come to visit and also will be problematic to the development of the attraction, so that access to the location is not difficult for visitors,

\section{Observation Result Data}

Based on the observations that the author has done so far it can be concluded as follows:

\section{a. Attractions}

The tourism potential that can be developed is the Ciburial spring swimming pool, and the spring pool itself, so in that location 3 ponds were built, the first was the Ciburial spring pool where everything e-ISSN: 2407-392X. p-ISSN: 2541-0857 
was still natural, the pond was still made of soil and no changes could be made. Because it will reduce its attractiveness, the second pool is specifically for children where the pool has a touch of man-made, so the beauty has disappeared, and the last is the pool for adults with the same model as the children's pool only the depth is different, and if there is development, it will focus on pool number two and number three, because only the pool that can be developed or enlarged, because the current conditions, the size is still very small is less large, not comparable with visitors.

Because the pool comes from a spring, that's what has been the main attraction for visitors, to try it, while the number one pool is not used for swimming because it is the main pool and at the same time the pool irrigates the number two and number three pools.

In addition to springs, the paragliding landing attraction is one of the attractions that can be enjoyed by visitors and also visitors can enjoy the beautiful panorama of the vast and green tea mountains plus the cool air. The tourist attraction is in accordance with attraction theory based on Cooper (2000),

"Attraction or attraction is the main product of a destination. Attractions related to what to see and what to do. What tourists can see and do in the destination. Attractions can be in the form of beauty and uniqueness of nature, local culture, heritage of historical buildings, and artificial attractions such as games and entertainment facilities. "

Based on this theory, attractions are tourist attractions in which there is something unique that attracts visitors. And these attractions can actually be combined with several existing attractions, such as making tour packages in which there are Paragliding, tea walks and Ciburial springs so that they become a single unit, and of course will increase income for all parties that exist both the manager and the surrounding community

\section{b. Accessibility}

Still with the same theory, Cooper (2000), according to Cooper's accessibility such as local transportation and the existence of a terminal, based on observations, the location of the Ciburial spring located in the southern Tugu can be reached by public transportation using public transportation 02 (Bogor - Cisarua) or can also use a mini cab with Bogor Cipanas route or when using a bus with the Bogor - Bandung route. In addition to public transport can be taken also by using 
private vehicles both two-wheeled and four-wheeled vehicles.

\section{c. Amenitas}

According to Cooper (2000) amenitas such as the availability of accommodation, restaurants, and travel agents while according to Middleton (2001):

"Amenitas or facilities in which there are akomoodasi, restaurant, transportation, activities, facilities, and services in which discuss the rental of equipment"

and the current one at Mata Ciburial, only provides swimming equipment such as tire rental at a price of Rp.5,000 / tire, for restaurants not available until now, for food only relying on street vendors, and before selling must be recorded first by the manager, and traders are required to pay a levy of Rp. 15,000 per month, in addition there are 5 gazebos, 2 canopies, 2 toilets that become one with flushing after swimming, and there are 4 trash cans with a fairly large size, and provided a tricycle rental for Rp. 15,000, the mosque is located close to the Ciburial spring and the parking area is divided into 3 points, namely, the first drop is close to the spring pool, the second point is above the plant, and the third point is above which is adjacent to the paragliding landing location.

\section{DISCUSSION}

\section{Potential Ciburial spring is a fitness tour based on observation}

The development of the Ciburial spring potential as a tourist has fulfilled the 3A aspect. Based on Cooper (2000), a benchmark for developing a tourism destination can be seen from the $3 \mathrm{~A}$ aspect which consists of Attraction, Accessibility and Amenity. With more management, Ciburial springs can develop optimally. Ciburial spring as a health tourism in Bogor Regency based on 3A aspects including:

\section{a. Accessibility}

Accessibility is a very important factor in the development of Ciburial spring tourism attractions. The main accessibility to the Ciburial spring is in accordance with the accessibility theory according to Cooper (2000),"Accessibility or accessibility is a means and infrastructure to get to a destination." Based on this theory, accessibility is a very important aspect to bring tourism to these destinations. And for now access to the location can be reached by using a variety of means of transportation, two-wheeled vehicles, four-wheeled vehicles, and public transportation, public transportation with the direction of Cisarua - Bogor or using the Bus with the aim to Cipanas or e-ISSN: 2407-392X. p-ISSN: 2541-0857 
Cianjur and the latter can use L -300 special transports from Bogor go to Cianjur, so all access can be used, as needed. And for hospitals the location is not far from the Ciburial spring

\section{b. Amenities}

The atmosphere in the Ciburial spring corresponds to Cooper's (2000) theory, "Facilities or amenities are all supporting facilities that can meet the needs and desires of tourist while in tourist destinations." Based on this theory, amenitas is the main support for tourists to get appropriate services when traveling. Here are some of the facilities in the Ciburial spring, namely parking lots, pondopo, canopy, public toilets, sign boards, information posts, security posts and places to wash after swimming.

\section{c. Attraction}

Tourism potential that can be developed in the Ciburial Spring, the spring itself, the properties of water from the spring is very good for health and fitness, a green and cool natural panorama coupled with paragliding sports activities. It can be developed into a fitness tour, its position is in the middle of nature and will be the only SPA that is located in the immediate nature, so the effect of fitness will be felt immediately, during the use of tea products for SPA ingredients which can be used for scrubs or for scrubs and can also be consumed as one of the best herbal drinks for health, especially green tea.

The tourist attraction is in accordance with attraction theory based on Cooper (2000),

"Attraction or attraction is the main product of a destination. Attractions related to what to see and what to do. What tourists can see and do in the destination. Attractions can be in the form of beauty and uniqueness of nature, local culture, heritage of historical buildings, and artificial attractions such as games and entertainment facilities. "

Based on this theory, attractions are tourist attractions in which there is something unique that attracts visitors.

\section{CONCLUTION}

Based on the analysis and discussion, it can be concluded that:

1. Visitors who come to Gunung Mas Agro Tourism especially the Ciburial spring, Tugu Selatan Village, until now have experienced a decline due to many other tourist attractions that grow whose position 
is along the road to the top, and in addition due to the location Gunung Mas, which has to go through several traffic jams.

2. After observing and analyzing and also adjusting to the existing theories, the development of the Ciburial spring, with the natural conditions, and seeing the uniqueness that its competitors do not have in the location of the $5 \mathrm{~km}$ to $15 \mathrm{~km}$ radius, suitable development is tourism development fitness / wellness tourism which currently has become a world trend and also in Indonesia, because in addition to having a good impact on health, and also from the economic side can increase the income of managers and surrounding communities, the development uses the $3 \mathrm{~A}$ theory issued by Kotler (attraction, access, amenities).

\section{ACKNOWLEDGEMENT}

The author like to thank the for Bogor School of Tourism (STP Bogor), who has given assistance in the form of finance, The author also thanked to the TRISAKTI School of Touism (STP Trisakti) who giving the opportunity to the author as a student of STP Trisakti
Postgraduate from to do Field research at Gunung Mas Puncak Area

\section{REFERENCE}

Rodrigues, A., Kastenholz, E., \& Rodrigues, A. (2010). Hiking as a wellness activity-an exploratory study of hiking tourist in Portugal, 333.

Kulezyeki, Luck, Rodrigues, A., \& Kastenholz, E. (2010). HIking as a welless activity-an exploratory study of hiking tourists in Portugal, 333.

Messerli, A., \& Oyama, Y. (2004). Health and Wellness tourism-global. Travel \& Tourism Analyst.

Szmigin; Carrigan , 2001; Feng, Hsiang Chang; Hsiou, Hsiang Liu; Kaung, Hwa Chen. (2013).

Hansmann et al., 2., Herzog et al, 1., Aurea, R., Elisabeth, K., \& and Apolonia, R. (2010). Hiking as a wellness activity-an exploratory study of hiking tourist in Portugal, 335.

Rodrigues et al., 2. (2010). HIking as a wellness activity-an exploratory study of hiking tourists in Portugal, 335.

Adam, T. 2., ; Kaung, H., Hsiou, H., \& Feng, H. (2013). Essential customer service factors and segmentation of older visitors within wellness tourism based on hot springs hotels, 123.

Smith and, K., Boulay, R., \& Dr.M.Hritz, N. (2012). Achieving Wellness through Tourism; Comparing INternational and U.S. Travelers. 
Pechlaner \&, F., \& Bachvarov \&, P. (2006).

Boulay, R., \& Hritz, D. (2012). Achievng Wellness throught Tourism:Comparing INternational and U.S. Travelers.

Crompton. (1979).

Boulay, R., \& Hritz, D. (2012). Achieving Wellness through Tourism:

Comparing International and U.S.

Travelers. 